\title{
Carlos Alvarado's Research on the Out-of-Body Experience
}

\author{
Harvey J. Irwin' \\ Manchester Metropolitan University
}

The prolific and remarkably diverse writings of Carlos Alvarado represent a major contribution to the parapsychological literature. In particular, two types of his contributions have played a valuable role in the development of many researchers' academic outlook, including my own. First, by virtue of Carlos's extensive familiarity with the historical literature he has frequently drawn our attention to historical precedents for some of the explanatory concepts emerging in the contemporary literature; the notion of transliminality is one such instance. Second, his knowledge of languages other than English has alerted us to important work published in non-English sources, thereby serving to broaden the discipline of parapsychology beyond a simple Anglo-American context.

In addition to these salutary influences on the field's perspective Carlos has contributed to our empirical knowledge of specific anomalous phenomena such as aura perception, synesthetic experiences, and travelling clairvoyance. A phenomenon of sustained interest to him was the out-of-body experience (OBE) in which experients have the impression that the "self" or center of awareness temporarily is located outside their physical body and typically can observe the immediate environment from this external position. Carlos's doctoral dissertation (Alvarado, 1997) focusses on the $\mathrm{OBE}$, and over the years approximately 40 of Carlos's papers address the experience, many of them co-authored by his devoted soul mate Nancy Zingrone. By way of humble homage to Carlos Alvarado I summarise here his principal contributions to OBE research.

The OBE is an intrinsically fascinating phenomenon and is a popular topic for college students' research projects. Such projects are certainly facilitated by Carlos's

1 Address correspondence to: Harvey J. Irwin, Ph. D., harvey.irwin@outlook.com 
periodic comprehensive reviews of OBE research and theoretical developments, perhaps most notably the chapter in Varieties of Anomalous Experience (Alvarado, 2000), and by his documentation of useful online resources that address the topic (e.g., Alvarado, 2010).

More fundamental in nature are his empirical reports of the phenomenology of the experience (e.g., the presence of specific sensations at the onset and/or the termination of the OBE) and some factors underlying variations in OBE phenomenology. Publications bearing on the latter identify a range of contextual correlates such as the distinction between a spontaneous experience and a deliberately induced experience, the frequency with which the person has had OBEs, the extent to which the context of occurrence incorporated a perceived threat to life, the extent and nature of concurrent physical activity, and the experient's personality and cognitive characteristics (e.g., Alvarado \& Zingrone, 2015; Alvarado, Zingrone, \& Dalton, 1999). Attention is also given to the aftereffects of the experience, a matter that few other researchers have investigated (e.g., Alvarado \& Zingrone, 2003). Several publications address the veridicality and ontological reality of the OBE and more broadly, the potential theoretical accounts of the experience; among the latter are purely psychological interpretations, the OBE as a psi-conducive state of consciousness, and the notion that something is "projected" or literally leaves the body during the experience (e.g., Alvarado, 2000, pp. 200-205). Among methodological issues Carlos examines the possibility that reports of an OBE may be embellished over time, and critically analyses the evidential status of case collections of "astral projection" such as those compiled by British researcher Robert Crookall (Alvarado, 2012).

As with Carlos's writings on other topics these papers seem to be permeated by his wonderful generosity of spirit; indeed, while I am reading his work I can almost sense his presence. In more objective terms, the conceptual breadth and the utility of Carlos's OBE publications are truly exceptional, and collectively they stand as an enduring testament to the quality of this remarkable man's life work in parapsychology.

\section{References}

Alvarado, C. S. (1997). Psychological and phenomenological characteristics of out-of-body experiences [Unpublished doctoral dissertation]. University of Edinburgh.

Alvarado, C. S. (2000). Out-of-body experiences. In E. Cardeña, S. J. Lynn, \& S. Krippner (Eds.), Varieties of anomalous experience: Examining the scientific evidence (1st ed., pp. 183-218). American Psychological Association. Doi: 10.1037/10371-006

Alvarado, C. S. (2010). Online resources for the history of out-of-body experiences and death-re- 
lated phenomena. Journal of Near-Death Studies, 28(3), 143-162. Doi: 10.17514/JNDS-201028-3-pl43-162

Alvarado, C. S. (2012). Explorations of the features of out-of-body experiences: An overview and critique of the work of Robert Crookall. Journal of the Society for Psychical Research, 76(2), 65-82.

Alvarado, C. S., \& Zingrone, N. L. (2003). Exploring the factors related to the aftereffects of out-ofbody experiences. Journal of the Society for Psychical Research, 67(3), 161-183.

Alvarado, C. S., \& Zingrone, N. L. (2015). Features of out-of-body experiences: Relationships to frequency, wilfulness and previous knowledge about the experience. Journal of the Society for Psychical Research, 79(2), 98-111.

Alvarado, C. S., Zingrone, N. L., \& Dalton, K. (1999). Out-of-body experiences: Alterations of consciousness and the five-factor model of personality. Imagination, Cognition and Personality, 18(4), 297-317. Doi: 10.2190/293K-3KW9-KYN8-TWKC 